\title{
Editorial
}

\section{Species Variation in the Islets of Langerhans}

\author{
J. M. Feldman
}

The ideal way to determine the defect in insulin secretion in diabetes mellitus would be to isolate and study the pancreatic islets of normal and diabetic subjects. Because of the great difficulty in obtaining suitable human pancreatic tissue, as well as the difficulty in isolating human islets, the majority of studies have employed pancreatic tissue from various species of animals. The tacit assumption is made that animal islets have many characteristics in common with human islets. However, each investigator seems to have his own preference with respect to both the animal species used, as well as the experimental design employed. One might ask if there is one particular species whose islets most closely resemble those of man and whether one particular experimental design gives the most relevant information about the behaviour of the islets.

Injection of the test substances into the intact animal gives some important information about its effect on insulin secretion. One limitation of this procedure is that the effect on insulin secretion may be a secondary rather than a primary effect of the substance. Thus, although ribose stimulates insulin secretion in intact dogs, it is as effective when injected into the right atrium as it is when injected into the pancreatic artery [1]. This suggests that the effect of this sugar on insulin output is due to an initial action at a site other than the pancreatic B cell.

In order to circumvent this problem, investigators have devised various in vitro systems. In the first of these systems, segments of animal pancreas were incubated in a flask with appropriate media and insulin secretion measured by bio- or, preferably, radioimmunoassay [2]. In systems in which rabbit or golden hamster (hamster) pancreas were studied, there was minimum degradation of secreted insulin by pancreatic proteolytic enzymes $[2,3]$. In systems using rat pancreas, there was substantial degradation of secreted insulin; however, even in the case of rat pancreas, this problem can be circumvented by employing insulin antiserum in the incubation flask [4].
In the second system, used to evaluate in vitro insulin secretion, the pancreatic islets are isolated from the acinar pancreas by either microdissection or the collagenase digestion technique [5, 6]. Although the microdissection technique has yielded very important information, it has the limitation that the microdissected islets usually come from obese hyperglycaemic mice (ob/ob) [6]. These mice cannot be considered to be truly normal mice, as they have marked insulin resistance and their islets secrete large quantities of insulin [6]. The collagenase isolation technique also has some limitations; for the collagenase preparation usually contains a variety of proteolytic enzymes. These enzymes may modify the surface structure of the islets. When compared with microdissected islets, collagenase-isolated islets show an increase or a decrease in basal and/or glucose-stimulated insulin secretion [6, 7]. Collagenase-isolated islets in a perifusion system respond to glucose or arginine stimulation, in a similar way to the isolated perfused pancreas [8]. However, though somatostatin inhibits glucose-stimulated insulin secretion from the perfused pancreas, it does not alter glucosestimulated insulin secretion from the perifused collagenase-isolated islets. This lack of inhibition may reflect subtle damage of the $B$ cell membrance during the isolation procedure. Thus, although collagenaseisolated islets are invaluable for biochemical studies of the islets, they have possible limitations with respect to secretion studies.

The third in vitro system is the isolated perfused pancreas system [9]. This has been very useful for carrying out dynamic secretions studies and probably gives the most reliable information about secretion. Because of the intact acinar tissue, it cannot be used for biochemical studies on the islets.

The fourth in vitro system is the tissue culture of pancreatic islets $[10,11]$. During this process, the cultured islets may lose some of the properties they have when removed from the intact organism. However, this system may prove increasingly useful in the future.

0012-186X/79/0016/0001/\$01.00 
Thus, one must take into account the particular experimental design used when one compares the response of islets from different species to the same stimulus. There remain, however, striking differences in the response of islets from different species to circulating substances (glucose and ketone bodies), intracellular substances (xylose and inosine), drugs (ethanol), and regulatory monoamines and their antagonists (norepinephrine, dopamine, isoproterenol, serotonin, haloperidol, methysergide, and cyproheptadine).

Glucose is one of the most consistently effective stimuli for insulin secretion. It stimulates insulin secretion from amphibian (organ culture) to man (isolated islets) $[12,13]$. In some species, such as the chicken (segments), glucose is effective only at very high concentrations (500-700 mg/dl) [14]. Although glucagon, theophylline, and dibutyryl cyclic AMPstimulate insulin release from human foetal pancreas (segments), glucose is ineffective [15]. Glucose stimulates insulin in a biphasic manner in almost all species evaluated. There are however qualitative differences in the second phase in different species. Using isolated perfused pancreas systems, the rat has a rising second phase, while the golden and chinese hamster both have a steady state second release phase $[9,16,17]$. Intravenous glucose results in a steady state second release in man [18]. Although this might be attributed to blunting of the rising second phase by hepatic insulin uptake, the second phase pattern in the human portal vein is steady state in character $[19,20]$.

Madison et al. demonstrated that infusion of the ketone bodies, 3-hydroxybutyrate and acetoacetate, stimulated insulin secretion in dogs [21]. They suggested that this may be an important feedback mechanism for the control of lipolysis in the fasting state. Infusions of 3-hydroxybutyrate or acetoacetate stimulate insulin release in intact rats, and 3-hydroxybutyrate stimulates insulin release from rat pancreas segments $[22,23]$. Neither ketone body stimulates insulin release from segments of rabbit pancreas [2]. 3-Hydroxybutyrate, but not acetoacetate, stimulates insulin secretion in man $[24,25]$.

Field et al. demonstrated an active pentose phosphate cycle in a human islet cell tumour, raising the possibility that a pentose intermediate of the cycle may be a signal for insulin release [26]. Intravenous xylitol stimulates insulin secretion in dogs, but does not alter insulin secretion in rabbits or man $[27,28$, 29]. Xylitol stimulates insulin secretion from isolated rat islets, but not from perfused rat pancreas, rat pancreas segments or rat pancreas organ cultures $[4,10$, $30,31]$. Xylitol does not stimulate insulin secretion from isolated mouse islets [32].

Inosine is a potent stimulator of insulin secretion from isolated mouse islets [33]. The mechanism of the stimulation appears to be conversion of the intracellular inosine to hypoxanthine and ribose-1phosphate through the action of islet nucleoside phosphorylase. The ribose part of the inosine molecule is then further metabolized through the pentose phosphate cycle [33]. This concept is supported by the observations of Campbell and Taylor that inosine stimulates insulin release from rat, but not rabbit, islets; rat islets contain nucleoside phosphorylase activity, while rabbit islets do not contain this enzyme [34]. In contrast, Jain and Logothetopoulos reported that inosine stimulates insulin secretion from mouse, but not rat, islets [35]. The importance of the experimental design is reinforced by the apparent conflicting results; for Campbell and Taylor used one-hour incubation periods in a physiological buffer, while Jain and Logothetopoulos used a 14-hour incubation in a tissue culture medium [35].

Ethanol inhibits glucose-stimulated insulin secretion from intact rats, hamster and rabbit pancreas segments, and isolated rat islets $[36,37,38]$. Ethanol also inhibits tolbutamide-stimulated insulin secretion from intact rats, but not from rabbit pancreas segments [36, 37]. In contrast, ethanol potentiates glucose-stimulated insulin secretion in intact man and pigs $[39,40]$. This difference may be due to formation of the principal metabolites of ethanol, acetaldehyde and acetate. Acetaldehyde inhibits glucosestimulated insulin secretion from rabbit, but not hamster, pancreas segments [37]. Acetate stimulates insulin secretion from hamster, but not rabbit, pancreas segments and potentiates glucose-stimulated insulin secretion in intact rats [36, 37].

There is considerable species variation in the quantity and type of monoamines (norepinephrine, dopamine and serotonin) in the pancreatic islets [41, 42]. Combined pharmacological and histological studies have shown that even animals that do not have stainable monoamines in their islets under basal conditions have a monoaminergic system in their islet cells $[41,42]$. There is also substantial species variation in the islet uptake of monoamines and their precursors, as well as in the content of the monoamine regulating enzyme, monoamine oxidase [43, 44].

A popular current concept is that the catecholamine control of insulin secretion is through an interaction between beta and alpha adrenergic receptors on the pancreatic B cell. Alpha adrenergic agonists, such as norepinephrine, are said to inhibit insulin secretion, and beta adrenergic agonists, such as isoproterenol, stimulate insulin secretion $[45,46]$. In almost all species studied, noradrenaline has consistently inhibited insulin secretion [46]. The observations with isoproterenol are more variable. Isoproterenol is a potent stimulus of insulin secretion in intact man and sheep and in the perfused dog pan- 
creas $[47,49]$. Isoproterenol is a weak stimulus for insulin secretion from perfused rat pancreas; it inhibits insulin secretion from segments of hamster and rabbit pancreas $[3,49,50]$.

The indolamine, serotonin, inhibits glucosestimulated insulin secretion from hamster, rabbit, and mouse pancreas and from intact rabbits $[3,51]$. Serotonin is a more potent inhibitor of insulin secretion from hamster pancreas than from rabbit or mouse pancreas [51]. This is due to the fact that the adrenergic nerves in hamster islets contain more norepinephrine than is found in rabbit or mouse islets. Serotonin is able to release this endogenous norepinephrine. Serotonin also stimulates insulin secretion from the intact dog [52], but the effect of serotonin on insulin secretion in intact man is equivocal. Various studies suggest that serotonin potentiates, inhibits, or has no effect on glucosestimulated insulin secretion [52-54]. These apparent discrepancies may be due to differences in experimental design.

There are a number of species differences in the effect of the monoamine antagonists on insulin secretion. The dopamine antagonist, haloperidol, has no effect on insulin secretion from rabbit pancreas segments, but inhibits insulin secretion from the perfused $\operatorname{dog}$ pancreas $[3,55]$. One patient who was receiving haloperidol had a severe spontaneous hypoglycaemic episode, accompanied by a marked elevated plasma insulin concentration [56].

The serotonin and histamine antagonist, cyproheptadine, inhibits insulin secretion from intact rats, from perifused rat islets and from hamster pancreas segments [57-59]. At the concentration used for in vitro studies, cyproheptadine is an effective monoamine oxidase inhibitor, and there is some evidence that this action may play a role in its inhibitory effect on insulin secretion from hamster pancreas [59]. In contrast, cyproheptadine potentiates glucose-stimulated insulin secretion from segments of rabbit pancreas, but has no effect on glucose-stimulated insulin secretion in intact man $[3,60]$. In therapeutic doses, cyproheptadine does not inhibit MAO in intact man [61].

Another serotonin antagonist, methysergide also potentiates insulin secretion from pieces of rabbit pancreas, but does not alter insulin secretion from pieces of hamster pancreas (methysergide is a very weak MAO inhibitor.) [3, 59]. As with cyproheptadine it does not alter glucose-stimulated insulin secretion in normal man [62].

It is obvious that there are great differences in the response of islets from different species. Although there are some possible mechanisms suggested for some of these differences (inosine, ethanol), the majority of the differences are presently inexplicable. The response to various agents is so diverse that one cannot presently determine which animal species has islets that most closely resemble those of man. Until this question has been resolved, it is preferable that we continue to conduct our studies on pancreatic islets from a variety of species and not restrict ourselves to a species that is, perhaps, not the most appropriate one for our major attention.

\section{References}

1. Goetz, F. C., Maney, J. W., Zaske, R.: Regulation of insulin secretion: the ribose responsive site. Diabetes 16, 511 (1967)

2. Coore, H. G., Randle, P. J.: Regulation of insulin secretion studied with pieces of rabbit pancreas incubated in vitro. Biochem. J. 93, 66-78 (1964)

3. Feldman, J. M., Quickel, K. E., Lebovitz, H. E.: Potentiation of insulin secretion in vitro by serotonin antagonists. Diabetes 21, 779-788 (1972)

4. Malaisse, W., Malaisse-Lagae, F., Wright, P. H.: A new method for measurement in vitro of pancreatic insulin secretion. Endocrinology 80, 99-108 (1967)

5. Lacy, P. E., Kostianövsky, M.: Method for the isolation of intact islets of Langerhans from the rat pancreas. Diabetes 16, 35-39 (1967)

6. Lernmark, $\AA$.: Isolated mouse islets as a model for studying insulin release. Acta Diabetol. Lat. 8, 649-679 (1971)

7. Atkins, T., Matty, A. J.: Metabolic viability of freehand microdissected and collagenase-isolated islets of Langerhans. J. Endocrinol. 46, 17-18 (1970)

8. Norfleet, W. T., Haymond, M.W., Pagliara, A. S., Matschinsky, F. M.: Collagenase induced modification of $\alpha$ - and $\beta$ cell secretory responses (Abstract 73), p. 73-87. Program of 57th Annual Meeting, Endocrine Society, 1975

9. Curry, D. L., Bennett, L. L., Grodsky, G. M.: Dynamics of insulin secretion by the perfused rat pancreas. Endocrinology 83, 572-584 (1968)

10. Lambert, A. E., Junod, A., Stauffacher, W., Jeanrenaud, J., Renold, A. E.: Organ culture of fetal rat pancreas I. insulin release induced by caffeine and by sugars and some derivatives. Biochim. Biophys. Acta 184, 529-539 (1969)

11. von Wasielewski, E., Chick, W. L.: Pancreatic beta cell culture. Amsterdam, Oxford: Excerpta Medica 1977

12. Gater, S., Balls, M.: Amphibian pancreas function in long term organ culture. Gen. Comp. Endocrinol, 33, 94-102 (1977)

13. Ashcroft, S. J. H., Bassett, J.M., Randle, P. J.: Isolation of human pancreatic islets capable of releasing insulin and metabolizing glucose in vitro. Lancet $1971 \mathrm{I}, 888-889$

14. Naber, S. P., Hazelwood, J.: In vitro insulin release from chicken pancreas. Gen. Comp. Endocrinol. 32, 495-504 (1977)

15. Milner, R. D. G., Ashworth, M. A., Barson, A. J.: Insulin release from human foetal pancreas in vitro. Horm. Metab. Res. 3, 353-354 (1971)

16. Curry, D. L., Bennett, L. L., Li, C. H.: Dynamics of insulin release by perfused hamster (Mesocriceta auratus) pancreas: effects of hypophysectomy, bovine and human growth hormone and prolactin. J. Endocrinol. 65, 245-251 (1975)

17. Gerhard, S. E., Ruhl, M.: Insulin secretion of the isolated perfused pancreas of the Chinese hamster (Cricetulus griseus). Acta Endocrinol. (Kbh.) 76, 302-318 (1974)

18. Lerner, R. L., Porte, D.: Uniphasic insulin responses to secretin stimulation in man. J. Clin. Invest. 49, 2276-2280 (1970)

19. Striffler, J. S., Curry, D. L.: Biphasic insulin by the liver in rat liver-pancreas preparations perfused in situ (Abstract 66), p. 89. Program of the 58th Annual Meeting, Endocrine Society, 1976

20. Blackard, W. G., Nelson, N. C.: Portal vein insulin concentrations in diabetic subjects. Diabetes 20, 286-288 (1971) 
21. Madison, L. L., Mebane, D., Unger, R., Lochner, A.: Evidence for physiological significance of a stimulatory feedback of ketone bodies on the B-cells. In: The Structure and Metabolism of the Pancreatic Islets. Brolin, S. E., Hellman B., Knutson, H. (Eds.), pp. 457-462. New York: MacMillan 1964

22. Hawkins, R. A., Alberti, K. G. M. M., Houghton, C. R. S. Williamson, D. H., Krebs, H. A.: The effect of acetoacetate on plasma insulin concentration. Biochem. J. 125, 541-544 (1971)

23. Malaisse, W. J., Malaisse-Lagae, F.: Stimulation of insulin secretion by noncarbohydrate metabolites. J. Lab. Clin. Med. 72, 438-448 (1968)

24. Pi-Sunyer, F. X., Sethi, S. S.: Stimulation of insulin secretion by sodium beta-hydroxybutyrate in man. Diabetes 21, 373 (1972)

25. Fajans, S. S., Floyd, J. C., Knopf, R. F., Conn, J. W.: A comparison of leucine and acetoacetate-induced hypoglycemia in man. J. Clin. Invest. 43, 2003-2008 (1964)

26. Field, J. B., Johnson, P., Herring, B., Weinberg, A.: Evidence for the hexose monophosphate pathway for glucose metabolism in human pancreatic B-cells. Nature 185, 468-469 (1960)

27. Hirata, Y., Fujisawa, M., Sato, H., Asano, T., Katsuki, S.: Blood glucose and plasma insulin responses to xylitol administrated intravenously in dogs. Biochem. Biophys. Res. Commun 24, 471-475 (1966)

28. Nijjar, M. S., Perry, W.F.: Effects of intravenous and oral infusion of monosaccharides on serum insulin levels in rabbits. Diabetes 19, 155-160 (1970)

29. Geser, K. A., Forster, H., Prols, H., Mehnert, H.: The lack of effect of xylitol on insulin secretion in man. Klin. Wochenschr. 45, 851-852 (1967)

30. Montague, W., Taylor, K. W.: Pentitols and insulin release by isolated rat islets of Langerhans. Biochem. J. 109, 333-339 (1968)

31. Grodsky, G. M., Batts, A. A., Bennett, L. L., Vcella, C., McWilliams, N. B., Smith, D.: Effects of carbohydrate on secretion of insulin from isolated rat pancreas. Am. J. Physiol. 205, 638-644 (1963)

32. Ashcroft, S. J. H., Weerasinghe, L. C. C., Bassett, J. M., Randle, P. J.: The pentose cycle and insulin release in mouse pancreatic islets. Biochem. J. 126, 525-532 (1972)

33. Capito, K., Hedeskov, C. J.: Inosine-stimulated insulin release and metabolism of inosine in isolated mouse pancreatic islets. Biochem. J. 158, 335-340 (1976)

34. Campbell, I. L., Taylor, K. W.: A species difference in nucleoside phosphorylase activity and inosine-stimulated insulin secretion in isolated islets of Langerhans. Biochem. J. 168, 591-593 (1977)

35. Jain, K., Logothetopoulos, J.: Metabolic signals produced by purine ribonucleosides stimulate proinsulin biosynthesis and insulin secretion. Biochem. J. 170, 461-467 (1978)

36. Shah, J. H., Wongsurawat, N., Aran, P.: Effect of ethanol on stimulus-induced insulin secretion and glucose tolerance. Diabetes 26, 271-277 (1977)

37. Bivens, C. H., Feldman, J.M.: Effeet of ethanol and its metabolites on insulin secretion. Q. J. Stud. Alcohol 35, 635-648 (1974)

38. Singh, S. P., Patel, D. G.: Ethanol influence on insulin release from isolated rat islets. Diabetes 27, 505 (1978)

39. Kuhl, C., Anderson, O., Jensen, S. L., Nielsen, O. V.: Effect of ethanol on the glucose-mediated insulin release in triply catheterized anesthetized pigs. Diabetes 25, 752-757 (1976)

40. Metz, R., Berger, S., Mako, M.: Potentiation of plasma insulin response to glucose by prior administration of alcohol. Diabetes 18, 517-522 (1969)

41. Cegrell, L.: The occurrence of biogenic monoamines in the mammalian endocrine pancreas. Acta. Physiol. Scand. [Suppl.] 314, 1-39 (1968)

42. Lebovitz, H. E., Feldman, J. M.: Pancreatic biogenic amines and insulin secretion in health and disease. Fed. Proc. 32, 1797-1802 (1973)
43. Mahony, C., Feldman, J. M.: Species variation in pancreatic islet monoamine uptake and action. Diabetes 26, 257-261 (1977)

44. Feldman, J. M., Chapman, B.: Characterization of pancreatic islet monoamine oxidase. Metabolism 24, 581-588 (1975)

45. Malaisse, W., Malaisse-Lagae, F., Wright, P. H., Ashmore, J.: Effects of adrenergic and cholinergic agents upon insulin secretion in vitro. Endocrinology 80, 975-978 (1967)

46. Woods, S. C., Porte, D.: Neural control of the endocrine pancreas. Physiol. Rev. 54, 596-619 (1974)

47. Robertson, R. P., Porte, D.: The glucose receptor: a defective mechanism in diabetes mellitus distinct from the beta adrenergic receptor. J. Clin. Invest. 52, 870-876 (1973)

48. Bassett, J. M.: Metabolic effects of catecholamines in sheep. Ausl. J. Biol. Sci. 23, 903-914 (1970)

49. Loubatieres-Mariani, M., Chapal, L., Ribes, G., Loutatieres, A.: Discrepancies in the response of the insulin secreting cells of the dog and rat to different adrenergic stimulating agents. Acta Diabetol. Lat. 14, 144-155 (1977)

50. Feldman, J. M., Boyd, A. E. III, Lebovitz, H. E.: Structural determinants of catecholamine action on in vitro insulin release. J. Pharmacol. Exp. Ther. 176, 611-621 (1972)

51. Quickel, K. E., Feldman, J. M., Lebovitz, H. E.: Inhibition of insulin secretion by serotonin and dopamine: species variation. Endocrinology 89, 1295-1302 (1971)

52. Federspil, G., Casara, D., Pedrazzoli, S., Sicolo, N., Scandellari, C.: In vivo studies on 5-hydroxytryptamine and insulin secretion in dogs and man. Diabetologia 10, 13-17 (1974)

53. de Leiva, A., Tanenberg, R. J., Anderson, G., Greenberg, B., Senske, B., Goetz, F. C.: Serotoninergic activation and inhibition: effects on carbohydrate tolerance and plasma insulin and glucagon metabolism. Metabolism 27, 511-520 (1978)

54. Feldman, J. M., Plonk, J. W., Bivens, C. H., Lebovitz, H. E.: Glucose intolerance in the carcinoid syndrome. Diabetes 24, 664-671 (1975)

55. Hermansen, K.: Haloperidol, a dopaminergic antagonist: somatostatin-like inhibition of glucagon and insulin release from the isolated, perfused canine pancreas. Diabetologia 15, 343-347 (1978)

56. Kojak, G., Barry, M. J., Gastineau, C. F.: Severe hypoglycemic reaction with haloperidol: Report of a case. Am. J. Psychol. 126, 573-576 (1969)

57. Wold, J. S., Longnecker, D. S., Fischer, L. J.: Species dependent pancreatic islet toxicity produced by cyproheptadine: alterations in beta cell structure and function. Toxicol. Appl. Pharmacol. 19, 188-201 (1971)

58. Richardson, B.P., McDaniel, M. L., Lacy, P.E.: Effects of cyproheptadine on insulin secretion by isolated perifused rat islets. Diabetes 24, 836-841 (1975)

59. Feldman, J. M., Chapman, B. A., Plonk, J. W.: Monoamine oxidase inhibition: a possible mechanism for cyproheptadineinduced alterations in insulin secretion. Life Sci. 15, 1121-1134 (1974)

60. Feldman, I. M., Bivens, C. H., Skyler, J. S., Lebovitz, H. E.; Effect of cyproheptadine administration on insulin secretion in acromegalic, diabetic and normal subjects. Horm. Metab. Res. 7, 279-283 (1975)

61. Feldman, J. M., Roche, J., Plonk, J. W.: Therapeutic doses of cyproheptadine do not inhibit monoamine oxidase in man. $\mathbf{J}$. Clin. Pharmacol. 16, 106-109 (1976)

62. Quickel, K. E., Feldman, J. M., Lebovitz, H. E.: Enhancement of insulin secretion in adult onset diabetics by methysergide maleate: evidence for an endögenous biogenic monoamine mechanism as a factor in the impaired insulin secretion in diabetes mellitus. J. Clin. Endocrinol. 33, 877-881 (1971)

Jerome M. Feldman, M. D.

Division of Endocrinology

Duke University Medical Center

Durham, NC 27710, USA 